\title{
Involvement of macrophage migration inhibitory factor in cancer and novel therapeutic targets (Review)
}

\author{
NADÈGE KINDT ${ }^{1}$, FABRICE JOURNE ${ }^{1,2}$, GUY LAURENT $^{3}$ and SVEN SAUSSEZ ${ }^{1,4}$ \\ ${ }^{1}$ Laboratory of Anatomy and Cellular Biology, Faculty of Medicine and Pharmacy, University of Mons, Mons 7000; \\ ${ }^{2}$ Laboratory of Oncology and Experimental Surgery, Institut Jules Bordet, Free University of Brussels, Brussels 1000; \\ ${ }^{3}$ Laboratory of Histology, Faculty of Medicine and Pharmacy, University of Mons, Mons 7000; \\ ${ }^{4}$ Department of Otorhinolaryngology, Faculty of Medicine, Free University of Brussels, Brussels 1000, Belgium
}

Received January 26, 2016; Accepted May 16, 2016

DOI: $10.3892 / \mathrm{ol} .2016 .4929$

\begin{abstract}
Macrophage migration inhibitory factor (MIF) was originally identified in 1966 by Bloom and Bennett as a pro-inflammatory cytokine involved in the inhibition of macrophage motility. Since then, studies have investigated the functional contribution of this pro-inflammatory cytokine in several immune diseases, including rheumatoid arthritis and lupus erythematous. Recently, MIF has been reported to be involved in a variety of neoplastic diseases. The present review discusses previous cancer research studies that have investigated the involvement of MIF in carcinogenesis, disease prognosis, tumor cell proliferation and invasion, and tumor-induced angiogenesis. Finally, potential therapeutic approaches based on the use of MIF antagonists and neutralizing antibodies are examined. The review concludes that MIF could be a good prognostic biomarker in several types of cancer, but also that the inhibition of MIF could represent a novel therapy against cancer.
\end{abstract}

\section{Contents}

1. Introduction

2. MIF and cancer

3. Conclusion

\section{Introduction}

Macrophage migration inhibitory factor (MIF) is a pro-inflammatory cytokine that was first identified in 1966

Correspondence to: Professor Sven Saussez, Laboratory of Anatomy and Cellular Biology, Faculty of Medicine and Pharmacy, University of Mons, 6 Avenue du Champ de Mars, Mons 7000, Belgium

E-mail: sven.saussez@umons.ac.be

Key words: migration inhibitory factor, cancer, cell proliferation, invasion, angiogenesis, cancer therapy in a study by Bloom and Bennett (1), which reported that $\mathrm{T}$ lymphocytes released a factor able to inhibit the random movement of macrophages. The MIF gene is localized on chromosome 22q11.2 and codes for a transcript 800 bp in length. The MIF protein is composed of 115 amino acids with a molecular weight of $12.5 \mathrm{kDa}$ in the monomeric form. The active form of MIF is a homotrimer: Each monomer exhibits two anti-parallel $\alpha$-helices and six $\beta$-strands (2). This cytokine shares homology with the bacterial enzyme 4-oxalocrotonate tautomerase (3). Additionally, in a study on melanin biosynthesis, MIF catalyzed the conversion of $D$-dopachrome to 5,6-dihydroxyindole-2-carboxylic acid and this was dependent on its tautomerase activity (4).

In addition to $\mathrm{T}$ lymphocytes, MIF is secreted by a variety of other cells, including epithelial cells, endothelial cells and macrophages (5). MIF also exhibits the properties of a stress hormone, as it is expressed at high concentrations in the anterior pituitary gland, from which its release is triggered by corticotrophin-releasing hormone (6). During inflammatory responses, MIF counterbalances the immunosuppressive activity of glucocorticoids. This effect may be explained by the fact that MIF inhibits mitogen-activated protein kinase (MAPK) phosphatase-1, which is induced by glucocorticoids (7). In addition, MIF has been implicated in several types of inflammatory diseases, including atherosclerosis, rheumatoid arthritis, systemic lupus erythematosus, inflammatory bowel disease, psoriasis and diabetes $(8,9)$. Therefore, at present, studies are focusing on the identification and development of pharmacological agents capable of interfering with MIF activity.

\section{MIF and cancer}

In addition to inflammatory diseases, MIF has also been demonstrated to be overexpressed in solid tumors, such as lung, colorectal, breast, cervical, prostate, and head and neck cancer, where it may exhibit a crucial function in tumor progression (cell proliferation and invasiveness) and tumor-induced angiogenesis (10-15). It is hypothesized that the latter processes are modulated by MIF binding to its cognate receptor, cluster of differentiation (CD)74 [also known as the invariant chain of the major histocompatibility complex class II] in association with 
CD44. While CD74 provides the binding site, downstream signal transduction pathways [MAPK and AKT pathways] are activated via CD44.

Globally, the MIF effects in cancer may be mainly explained by signaling through the CD74 receptor, since we recently showed that i) CD74 is upregulated in oral cavity carcinomas compared with benign lesions, ii) knockdown of CD74 in the murine squamous cell carcinoma SCCVII cell line decreases in vitro proliferation, migration, MMP9 secretion and VEGF production, and iii) SCCVII CD74-knockdown cells orthotopically inoculated in mice have a weaker growth capacity than scramble cells (16).

However, additional receptors may be involved in the effects of MIF in cancer insofar as its interaction with the chemokine receptor CXCR4 may induce metastasis. Indeed, Dessein et al (17) showed that MIF binding to CXCR4 was associated with invasion and metastasis in human colon carcinoma cells.

MIF and carcinogenesis. Carcinogenesis refers to the processes by which normal cells are transformed into cancer cells. Several clinical studies have revealed that MIF expression is increased in cancer tissues compared with corresponding normal tissues. For example, a previous study demonstrated that in gastric cancer, positive MIF expression rates were 12,52 and $96 \%$ in normal mucosal, gastritis and gastric cancer tissues, respectively (18). Similar observations have also been reported in pancreatic cancer, melanoma, hepatocellular carcinoma, malignant glioma and cervical adenocarcinoma (13,19-22).

Furthermore, Zhao et al (23) demonstrated that serum MIF levels may aid to differentiate cancer patients with hepatocellular carcinoma from individuals with other liver diseases, such as cirrhosis, when using a reference threshold of $35.3 \mathrm{ng} / \mathrm{ml}$. Similarly, De Souza et al (24) reported that in oral squamous cell carcinoma patients, MIF serum levels decreased following tumor resection and thus, serum MIF was proposed as a biomarker.

In our previous studies, a significant increase in MIF immunostaining was observed in hypopharyngeal carcinoma, oral cavity carcinoma and laryngeal carcinoma when compared with normal epithelium, and low and high-grade dysplasia and carcinoma, respectively $(15,25,26)$. In addition, our previous study also revealed that in breast cancer patients, MIF expression was increased in cancer tissues when compared with tumor-free breast tissues in glandular and stromal compartments (12). Therefore, these results provide compelling evidence that MIF is involved in tumor biology.

MIF and disease prognosis. Kamimura et al (27) reported that low nuclear MIF expression was correlated with a worse prognosis in lung adenocarcinoma and thus, it was postulated that the intracellular distribution of MIF has prognostic significance. By contrast, subsequent studies indicated that high MIF expression in cancer was correlated with poor patient survival. For example, Tomiyasu et al (28) demonstrated that high MIF expression in lung cancer tissues was correlated with heavy smoking status and a poorer prognosis. Furthermore, overexpression of MIF correlates with a worse prognosis in hepatocellular carcinoma, which is characterized by a high frequency of recurrence, large tumor size, high tumor-node-metastasis stage and prominent vascular invasion $(23,29)$. In oral squamous cell carcinoma, increased MIF expression correlates with a higher pathological (p)T and $\mathrm{pN}$ status, positive perineural invasion and tumor depth (30). In addition, in metastatic melanoma, high MIF expression is associated with faster disease progression (31). In addition, high MIF mRNA expression in pancreatic ductal carcinoma correlates with a poor survival when compared with tumors exhibiting low MIF mRNA expression (32).

With regard to circulating MIF, Zhao et al (23) reported that an increase in MIF serum level to $90 \mathrm{ng} / \mathrm{ml}$ (normal value, $15 \mathrm{ng} / \mathrm{ml}$ ) corresponded to a poor prognosis for patients with hepatocellular carcinoma. A similar observation was reported in colorectal cancer, where serum MIF levels were elevated in patients with hepatic or lymphoid metastasis when compared with those without metastasis (11). Furthermore, gastric cancer patients with a serum MIF level of $\geq 6,600 \mathrm{pg} / \mathrm{ml}$ exhibited a poorer prognosis than those with lower serum MIF levels (33).

In our previous study, it was demonstrated that serum MIF levels were higher in head and neck squamous cell carcinoma patients compared with healthy volunteers, and high MIF immunostaining in tumor tissues was found to correlate with a poor prognosis in terms of local tumor recurrence, nodal metastasis involvement and overall survival (15). Recently, similar results have been reported in oral squamous cell carcinoma and gastric cancer $(30,34)$. Overall, these clinical studies indicate that MIF expression levels in serum and tumor tissue may be of prognostic value in numerous cancer types.

MIF and cell proliferation. Shi et al (35) demonstrated that MIF interacts with the CD74/CD44 receptor complex in stably transfected mammalian kidney COS-7/M6 cells, leading to MIF signal transduction via the activation of Src, Ras, MAPK kinase and extracellular-signal-regulated kinase (ERK). It is hypothesized that this pathway may account for enhanced proliferative activity (31). Indeed, the interaction of MIF with its receptor CD74 results in the stimulation of ERK1/2 leading to cyclin D1 expression (36) and enhancement of proliferative activity (35). In addition, MIF may enhance cell proliferation by activating not only the ERK1/2 pathway but also the phosphoinositide 3-kinase/AKT pathway. Notably, in a previous study, immunocytochemistry and western blotting revealed that the addition of recombinant human MIF to the cell medium of the gastric cancer MGC-803 cell line resulted in increased AKT phosphorylation (37).

MIF has been also reported to act as a potent inhibitor of the transcriptional activity of $\mathrm{p} 53$ by direct interaction between MIF and p53, and stabilization of the p53-MDM2 complex (38). This association prevents p53 translocation from the cytoplasm to the nucleus, and consequently represses the p53-induced cell cycle arrest and apoptosis, further supporting cell survival.

Several studies have confirmed that MIF contributes to cell proliferation in cancer. One previous study demonstrated that MIF expression was downregulated by short hairpin (sh)RNA in the murine ovarian cancer ID8 cell line, and the proliferation of inoculated tumor cells was reduced when compared with mock-transfected cells, as revealed by a decrease in the 
percentage of Ki-67-immunopositive cells (39). MIF-silencing studies have revealed comparable reductions in the tumor cell proliferation of human melanoma and hepatocellular carcinoma cell lines, whereby a decrease in cyclin D1 expression was reported in vitro and in vivo, respectively $(31,20)$. Another study reported that cyclin-dependent kinase 4 , cyclin D2 and cyclin E2 expression was downregulated following MIF-knockdown in HeLa 229 cells (22). In hepatocellular carcinoma, increased MIF expression, induced by cell transfection, potentiated the promoter activity of the hepatopoietin gene (a mediator involved in liver regeneration), leading to enhanced cell proliferation (40). Hu et al (41) also demonstrated that MIF potentiates cell proliferation, as the release of MIF from human hepatic sinusoidal endothelial cells (HHSECs) increased colorectal carcinoma cell proliferation. Notably, nude mice injected with colorectal cell lines mixed with mock-transfected HHSECs developed larger tumors than mice injected with cancer cells mixed with anti-MIF short hairpin (sh)RNA-transfected HHSECs (41).

Pharmacological inhibition of MIF by small molecule antagonists reduces cell proliferation. For example, in a previous study, a BrdU assay revealed that in glioblastoma cell lines treated with isoxazoline (ISO)-1, cell proliferation was inhibited in a concentration-dependent manner (42). Similarly, the use of MIF or CD74 neutralizing antibodies has been demonstrated to inhibit human prostate cancer cell (DU-145) proliferation (14).

In our previous study (15), shRNA-mediated MIF-knockdown in a murine squamous cell carcinoma cell line (SCCVII) decreased cell proliferation when compared with a control scramble shRNA cell line. These findings were confirmed in vivo by the observed reduction in tumor growth following injection of the SCCVII MIF-knockdown cells into $\mathrm{C} 3 \mathrm{H} /$ Hen mice compared with mice inoculated with scramble RNA-transfected cells (15). Finally, treatment of SCCVII cells with the MIF inhibitor 4-IPP (4-iodo-6-phenylpyrimidine) resulted in a dose-dependent decrease in cell proliferation (43). Thus, these findings indicate that MIF exhibits a critical function in tumor cell proliferation via its CD74 receptor, which activates the MAPK and AKT pathways.

MIF and tumor cell invasion. Tumor invasion and metastasis are highly critical in cancer progression. Several studies have indicated that MIF contributes to cell invasiveness in cancer. Notably, Rendon et al (10) revealed that in lung adenocarcinoma, MIF promotes Ras-related C3 botulinum toxin substrate 1 activity and thus, tumor cell motility via lipid raft activation. Another study reported that colorectal cancer cells cultured in medium conditioned with mock-transfected HHSECs exhibit increased intracellular F-actin expression compared with cells cultured in medium conditioned by anti-MIF shRNA-transfected HHSECs, indicating that cytoskeletal remodeling promotes colorectal cancer cell migration (41). Ren et al (44) revealed that decreased MIF expression in a neuroblastoma cell line reduces cell invasiveness in vitro and metastasis formation in vivo: $70 \%$ of athymic nude mice injected intravenously with MIF-expressing cells developed lung metastasis, whereas only $10-20 \%$ of mice developed lung metastasis when MIF was underexpressed. Furthermore, exposure to antibodies raised against MIF or CD74 has been shown to block the in vitro migration of prostate cancer DU-145 cells through Matrigel-coated membranes (14). In pancreatic cancer cell lines, the overexpression of MIF was associated with an increase in cell invasiveness in vitro and in vivo, with distant metastasis to the liver, spleen, lymph nodes and intestine (32). Furthermore, the MIF-associated promotion of cell invasiveness in vitro has also been demonstrated in colorectal carcinoma, nasopharyngeal carcinoma, adenoid cystic carcinoma and oral squamous cell carcinoma $(11,30,45,46)$. Notably, matrix metalloproteinase-9 (MMP-9) expression appears to be correlated with MIF expression, as positive immunostaining of MIF increases with that of MMP-9, and MMP-9 is associated with cell invasion in adenoid cystic carcinoma tissue (46).

Consistent with these studies, in our previous study, SCCVII cells treated with 4-IPP exhibited a significantly lower capacity for migration through Matrigel-coated membranes when compared with untreated cells, which demonstrated the function of MIF in cell invasion (43). Taken together, these observations indicate the involvement of MIF in tumor invasion and metastasis.

MIF and angiogenesis. Angiogenesis is essential for tumor progression, as neovascularization sustains tumor cell activity, survival and dissemination (47). Hypoxia promotes vessel growth via activation of proliferation and migration of endothelial cells. This involves stabilization of hypoxia-induced factor- $1 \alpha$ (HIF-1 $\alpha$ ) through two methods that link MIF and HIF1 $\alpha$ : i) In the extracellular environment, MIF binding to CD74 induces direct activation of HIF1 $\alpha$, and ii) in the intracellular compartment, MIF can bind Jab/CSN5, which regulates the stability of HIF1 $\alpha$ by preventing its hydroxylation (48), leading to the expression of pro-angiogenic factors such as IL-8 and VEGF. In this context, MIF is involved in angiogenesis, demonstrated most notably by a study in breast cancer tissue, whereby a correlation was identified between MIF and IL-8 expression (49). The same study also demonstrated that increased levels of serum MIF were correlated with an increase in IL-8 serum level (49). The association between MIF and IL- 8 was also confirmed in vitro: The addition of recombinant human MIF to breast cancer MDA-MB-231 and MCF7 cell line culture medium stimulated the secretion of VEGF and IL-8 (50). The increase in VEGF mRNA expression following exposure to recombinant human MIF was also reported in bladder cancer (51). Similarly, in non-small cell lung cancer, two studies reported that the level of CXC chemokine increased with MIF expression (51) and that MIF is required to bind its CD74 receptor to subsequently activate the transcription of CXCL8 and VEGF genes (52), which confirms that MIF is implicated in angiogenesis. In addition, studies have demonstrated that MIF immunostaining correlates with tumor microvessel density in hepatocellular carcinoma, and that recombinant human MIF stimulates endothelial tube formation in vitro, as demonstrated by human umbilical vein endothelial cell assays (53). Similarly, addition of exogenous MIF resulted in an increase of VEGF mRNA in the colorectal LoVo cell line (11). In addition, a previous study revealed that the $\mathrm{MIF}^{-/-}$mouse model of melanoma exhibits reduced vessel density compared with the wild-type model, as demonstrated by decreased immunostaining of the endothelial marker CD31 in B16-F10 tumors (54). Fu et al (55) reported that hypoxia in a $3 \% \mathrm{O}_{2}$ atmosphere increases MIF expression in human vascular 
Table I. Overview of previous literature investigating the function of MIF and/or CD74 in carcinogenesis, prognosis, proliferation, invasion, angiogenesis and reported responses to targeted therapy.

\begin{tabular}{|c|c|c|c|c|c|c|}
\hline Cancer type & $\begin{array}{c}\text { Carcinogenesis }^{\mathrm{a}}, \\
\text { refs. }\end{array}$ & $\begin{array}{l}\text { Prognosis }{ }^{\mathrm{b}}, \\
\text { refs. }\end{array}$ & $\begin{array}{l}\text { Proliferation }^{\mathrm{c}}, \\
\text { refs. }\end{array}$ & $\begin{array}{l}\text { Invasion }^{\mathrm{d}}, \\
\text { refs. }\end{array}$ & $\begin{array}{c}\text { Angiogenesis }{ }^{\mathrm{e}}, \\
\text { refs. }\end{array}$ & $\begin{array}{l}\text { Therapy }{ }^{\mathrm{f}}, \\
\text { refs. }\end{array}$ \\
\hline Adenoid cystic carcinoma & & & & 4 & & 45 \\
\hline Bladder & & & & & 50 & \\
\hline Breast & 12 & & & & 49 & \\
\hline Cervical & 13 & & & & & \\
\hline Colorectal & & 11 & 41 & 11,41 & 11 & 56 \\
\hline Gastric & 18 & 33,34 & 37 & & & \\
\hline Glioma & 22 & & 42 & & & \\
\hline Head and neck & $24,25,26,15$ & 30,15 & & $30,43,45$ & & 43 \\
\hline Liver & 21,23 & 23,29 & 21,40 & & 53 & \\
\hline Lung & & 28 & & 10 & 51,52 & 57 \\
\hline Melanoma & 20 & 31 & 31 & & 54 & 56 \\
\hline Multiple myeloma & & & & & & 59 \\
\hline Neuroblastoma & & & & 44 & & \\
\hline Pancreatic & 19 & 32 & & 32 & & \\
\hline Prostate & & & 14 & 14 & & 58 \\
\hline
\end{tabular}

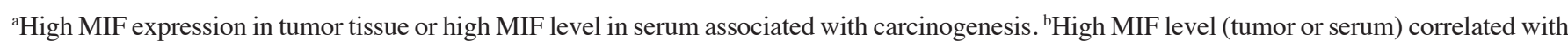
short patient survival time. ${ }^{~}$ Function of MIF in proliferation, as reported using MIF-silencing strategies $(21,31,41)$, MIF inhibition by antagonist $(42,43)$, MIF or CD74 neutralizing antibodies (14), MIF knock-in (40) and recombinant MIF (40). ${ }^{\mathrm{d}}$ Involvement of Ras-related C3 botulinum toxin substrate 1 (10), F-actin (41), N-Myc, Ras, cMet, tropomyosin receptor kinase B (44) and matrix metalloproteinase-9 (46) in MIF-induced invasion. ${ }^{\mathrm{e} F u n c t i o n}$ of interleukin-8 (49), vascular endothelial growth factor (50,52), CXC (51), chemokine (C-X-C motif) ligand 8 (52) and

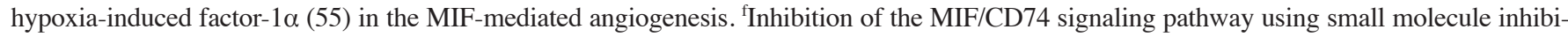
tors $(43,46,56,57)$ MIF (58) and CD74 (59) neutralizing antibodies. MIF, migration inhibitory factor; CD, cluster of differentiation.

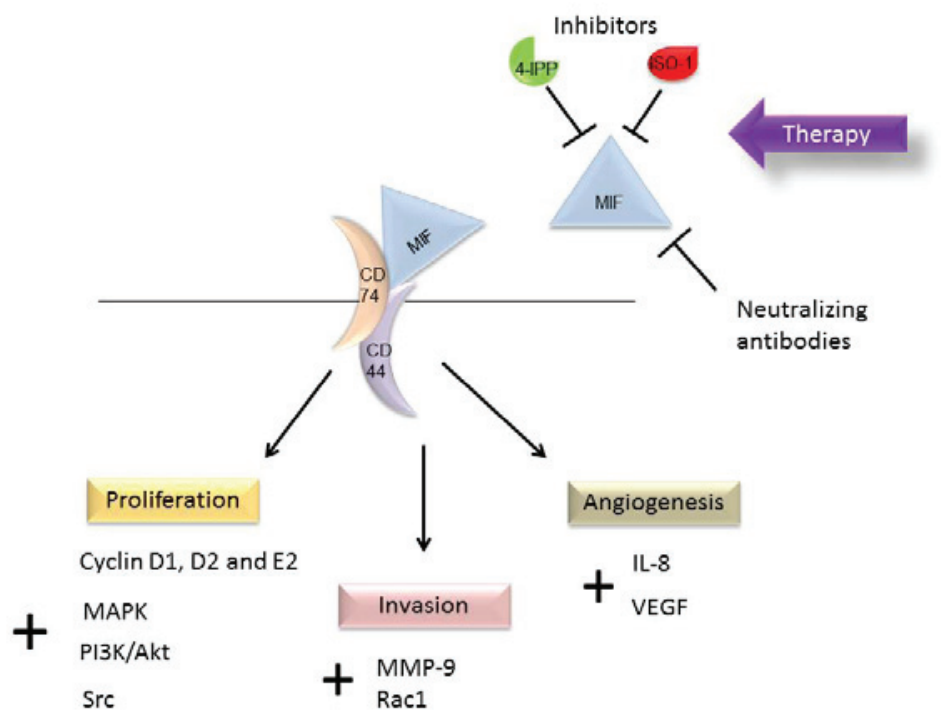

Figure 1. Schematic representation of the involvement of MIF in cancer, which affects several pathways in proliferation, invasion and angiogenesis, via interaction with its membrane receptor, CD74. Small molecule inhibitors, 4-IPP and ISO-1, and neutralizing antibodies have demonstrated an inhibitory effect on MIF. MIF, migration inhibitory factor; CD, cluster of differentiation; 4-IPP, 4-iodo-6-phenylpyrimidine; ISO-1, isoxazoline-1; IL, interleukin; MMP-9, matrix metalloproteinase-9; MAPK, mitogen-activated protein kinase; PI3K, phosphoinositide 3-kinase; VEGF, vascular endothelial growth factor; Rac1, Ras-related C3 botulinum toxin substrate 1 .

smooth muscle cells, further supporting the hypothesis that MIF and HIF-1 $\alpha$ mediate the response to hypoxia in such a model.
Therefore, these results demonstrate the function of MIF in angiogenesis. 
MIF and cancer therapy. MIF may present a novel therapeutic target in the field of oncology. The inhibition of the effect of MIF on tumor cells may be achieved by the use small molecule inhibitors, such as ISO-1 and 4-IPP, with high bioavailability and low toxicity, by the inhibition of MIF activity by neutralizing antibodies and by targeting its receptor, CD74.

The small inhibitory agents ISO-1 and 4-IPP have been demonstrated to inhibit the effects of MIF in cancer. ISO-1 exerts an inhibitory action on cell migration and invasion in vitro in adenoid cystic carcinoma, as demonstrated by a decrease in MMP-9 expression (46). Additionally, an analog of ISO-1, ISO-66, has recently been reported to be active in melanoma and colon cancer models, where it decreases tumor growth by stimulating an antitumor immune response in vivo (56). Regarding head and neck carcinoma, our previous study investigated the effect of 4-IPP on SCCVII cells and reported that the pharmacological inhibition of MIF resulted in impaired proliferation and invasiveness in vitro (43). Recently, Mawhinney et al (57) developed a novel inhibitor of MIF enzymatic activity (SCD-19), which was demonstrated to markedly inhibit the growth of nascent and established murine Lewis lung carcinoma.

The efficacy of human anti-MIF antibodies in human carcinoma has been reported by Hussain et al (58). The study revealed that the anti-MIF antibodies, BaxG03 and BaxB0, inhibit cell proliferation via the reduction of the phosphorylation of ERK1/2 and AKT in prostate cancer cell lines. It was also revealed that these antibodies decreased the migration of the PC3 cell line, with a half-maximal inhibition in the range of 2-10 $\mathrm{nm} / 1$. In addition, the study evaluated the in vivo efficacy of several anti-MIF antibodies (BaxG03, BaxB01 and BaxM159) in a xenograft model of prostate cancer and observed that the tumor size was reduced in mice that were administered antibodies for 30 days when compared with the control. Furthermore, the number of Ki-67-positive cells diminished after treatment compared with the control. In this study, the median effective dose was $8-14 \mathrm{mg} / \mathrm{kg}$ (58).

Regarding the mechanism of action of MIF, its receptor, CD74, may also present a promising therapeutic target to inhibit MIF signaling. In this context, a CD74 specific monoclonal antibody, milatuzumab, has been developed, which has been reported to enhance the action of doxorubicin in multiple myeloma cell lines (59). At present, a multiple myeloma phase I clinical trial combining milatuzumab and doxorubicin is ongoing (clinicaltrials.gov identifier, NCT01101594).

In our previous study, the effect of MIF underexpression on mouse survival following inoculation with SCCVII cells and subsequent treatment with cisplatin or 5-fluorouracil was evaluated (15). The results revealed that the tumors growing after the injection of MIF-knockdown cells were more sensitive to cisplatin ( $4 \mathrm{mg} / \mathrm{kg}$ twice a week for 2 weeks) and 5 -fluorouracil (20 mg/kg daily for 4 days) treatment than tumors developing from control cells, which further supports the hypothesis that MIF downregulation may potentiate the effect of chemotherapy agents.

Furthermore, a recent study reported that pharmacological inhibition of the ATPase activity of heat shock protein 90 (HSP90) resulted in the degradation of MIF in numerous types of cancer cell (60). Thus, targeting HSP90 may present a novel strategy for the inhibition of MIF in cancer.

\section{Conclusion}

In this review, the effect of MIF on tumor cell proliferation, migration and tumor-induced angiogenesis in clinical and experimental studies was discussed (Table I). Overexpression of MIF in tumor tissue, as well as high levels of MIF in patient serum, have demonstrated prognostic value associated with a short survival time. The poor clinical outcome of cancer patients exhibiting high MIF expression may be explained by its potentiating effects on proliferation, invasion and angiogenesis (Fig. 1). Indeed, binding of MIF to its receptor may stimulate the MAPK pathway and inhibit $\mathrm{p53}$, each positively impacting tumor cell proliferation and survival. In addition, the overexpression of MIF was correlated with the overexpression of MMP-9, further supporting its role in invasiveness. Furthermore, the action of MIF on angiogenesis may occur through the activation of HIF1 $\alpha$, and subsequently, the production of pro-angiogenic factors. A number of the effects of MIF may be driven by interaction with its membrane receptor CD74, while interaction with the chemokine receptor CXCR4 has also been proposed. Significantly, MIF also inhibits p53, inhibiting cell cycle arrest and apoptosis (Fig. 1). Altogether, such data provides a novel understanding of the potential role of MIF in the mechanisms of resistance to cancer therapy.

Thus, as MIF is implicated in numerous aspects of cancer progression, via direct activation of its CD74 receptor and direct inhibition of the tumor suppressor p53, inhibition of this factor and/or of its receptor may present a novel treatment strategy against cancer, alone or in combination with conventional, as well as targeted therapies.

\section{Acknowledgements}

The present review was supported by a grant (no. 7.4656.14) from the National Fund for Scientific Research and the Honorary Senior Research Associate of the National Fund for Scientific Research (Belgium).

\section{References}

1. Bloom and Bennett: Mechanism of a reaction in vitro associated with delayed-type hypersensitivity. Science 153: 80-82, 1966.

2. Sun HW, Bernhagen J, Bucala R and Lolis E: Crystal structure at 2.6-A resolution of human macrophage migration inhibitory factor. Proc Natl Acad Sci USA 93: 5191-5196, 1996.

3. Leng L and Bucala R: Insight into the biology of macrophage migration inhibitory factor (MIF) revealed by the cloning of its cell surface receptor. Cell Res 16: 162-168, 2006.

4. Rosengren E, Bucala R, Aman P, Jacobsson L, Odh G, Metz CN and Rorsman $\mathrm{H}$ : The immunoregulatory mediator macrophage migration inhibitory factor (MIF) catalyzes a tautomerization reaction. Mol Med 2: 143-149, 1996.

5. Conroy H, Mawhinney L and Donnelly SC: Inflammation and cancer: Macrophage migration inhibitory factor (MIF)-the potential missing link. QJM 103: 831-836, 2010.

6. Nishino T, Bernhagen J, Shiiki H, Calandra T, Dohi K and Bucala R: Localization of macrophage migration inhibitory factor (MIF) to secretory granules within the corticotrophic and thyrotrophic cells of the pituitary gland. Mol Med 1: 781-788, 1995.

7. Roger T, Chanson AL, Knaup-Reymond M and Calandra T: Macrophage migration inhibitory factor promotes innate immune responses by suppressing glucocorticoid-induced expression of mitogen-activated protein kinase phosphatase-1. Eur J Immunol 35: 3405-3413, 2005.

8. Santos LL and Morand EF: Macrophage migration inhibitory factor: A key cytokine in RA, SLE and atherosclerosis. Clin Chim Acta 399: 1-7, 2009. 
9. Sánchez-Zamora YI and Rodriguez-Sosa M: The role of MIF in type 1 and type 2 diabetes mellitus. J Diabetes Res 2014: 804519, 2014.

10. Rendon BE, Roger T, Teneng I, Zhao M, Al-Abed Y, Calandra T and Mitchell RA: Regulation of human lung adenocarcinoma cell migration and invasion by macrophage migration inhibitory factor. J Biol Chem 282: 29910-29918, 2007.

11. He XX, Chen K, Yang J, Li XY, Gan HY, Liu CY, Coleman TR and Al-Abed Y: Macrophage migration inhibitory factor promotes colorectal cancer. Mol Med 15: 1-10, 2009.

12. Richard V, Kindt N, Decaestecker C, Gabius HJ, Laurent G, Noël JC and Saussez S: Involvement of macrophage migration inhibitory factor and its receptor (CD74) in human breast cancer. Oncol Rep 32: 523-529, 2014

13. Guo P, Wang J, Liu J, Xia M, Li W and He M: Macrophage immigration inhibitory factor promotes cell proliferation and inhibits apoptosis of cervical adenocarcinoma. Tumour Biol 36: 5095-5102, 2015.

14. Meyer-Siegler KL, Iczkowski KA, Leng L, Bucala R and Vera PL: Inhibition of macrophage migration inhibitory factor or its receptor (CD74) attenuates growth and invasion of DU-145 prostate cancer cells. J Immunol 177: 8730-8739, 2006.

15. Kindt N, Preillon J, Kaltner H, Gabius HJ, Chevalier D, Rodriguez A, Johnson BD, Megalizzi V, Decaestecker C, Laurent G and Saussez S: Macrophage migration inhibitory factor in head and neck squamous cell carcinoma: Clinical and experimental studies. J Cancer Res Clin Oncol 139: 727-737, 2013.

16. Kindt N, Lechien JR, Nonclercq D, Laurent G and Saussez S: Involvement of CD74 in head and neck squamous cell carcinomas. J Cancer Res Clin Oncol 140: 937-947, 2014.

17. Dessein AF, Stechly L, Jonckheere N, Dumont P, Monté D, Leteurtre E, Truant S, Pruvot FR, Figeac M, Hebbar M, et al Autocrine induction of invasive and metastatic phenotypes by the MIF-CXCR4 axis in drug-resistant human colon cancer cells. Cancer Res 70: 4644-4654, 2010.

18. He XX, Yang J, Ding YW, Liu W, Shen QY and Xia HH: Increased epithelial and serum expression of macrophage migration inhibitory factor (MIF) in gastric cancer: Potential role of MIF in gastric carcinogenesis. Gut 55: 797-802, 2006

19. Tan L, Ye X, Zhou Y, Yu M, Fu Z, Chen R, Zhuang B, Zeng B, Ye $\mathrm{H}, \mathrm{Gao} \mathrm{W}$, et al: Macrophage migration inhibitory factor is overexpressed in pancreatic cancer tissues and impairs insulin secretion function of $\beta$-cell. J Transl Med 12: 92, 2014.

20. Heise R, Vetter-Kauczok CS, Skazik C, Czaja K, Marquardt Y, Lue H, Merk HF, Bernhagen J and Baron JM: Expression and function of macrophage migration inhibitory factor in the pathogenesis of UV-induced cutaneous nonmelanoma skin cancer. Photochem Photobiol 88: 1157-1164, 2012.

21. Huang XH, Jian WH, Wu ZF, Zhao J, Wang H, Li W and Xia JT: Small interfering RNA (siRNA)-mediated knockdown of macrophage migration inhibitory factor (MIF) suppressed cyclin D1 expression and hepatocellular carcinoma cell proliferation. Oncotarget 5: 5570-5580, 2014.

22. Mittelbronn M, Platten M, Zeiner P, Dombrowski Y, Frank B, Zachskorn C, Harter PN, Weller $\mathrm{M}$ and Wischhusen $\mathrm{J}$ : Macrophage migration inhibitory factor (MIF) expression in human malignant gliomas contributes to immune escape and tumour progression. Acta Neuropathol 122: 353-365, 2011.

23. Zhao YM, Wang L, Dai Z, Wang DD, Hei ZY, Zhang N, Fu XT, Wang XL, Zhang SC, Qin LX, et al: Validity of plasma macrophage migration inhibitory factor for diagnosis and prognosis of hepatocellular carcinoma. Int J Cancer 129: 2463-2472, 2011

24. De Souza MB, Curioni OA, Kanda JL and DE Carvalho MB: Serum and salivary macrophage migration inhibitory factor in patients with oral squamous cell carcinoma. Oncol Lett 8: 2267-2275, 2014

25. Cludts S, Decaestecker C, Johnson B, Lechien J, Leroy X, Kindt N, Kaltner H, André S, Gabius HJ and Saussez S: Increased expression of macrophage migration inhibitory factor during progression to hypopharyngeal squamous cell carcinoma. Anticancer Res 30: 3313-3319, 2010

26. Kindt N, Lechien J, Decaestecker C, Rodriguez A, Chantrain G, Remmelink M, Laurent G, Gabius HJ and Saussez S: Expression of macrophage migration-inhibitory factor is correlated with progression in oral cavity carcinomas. Anticancer Res 32: 4499-4505, 2012.
27. Kamimura A, Kamachi M, Nishihira J, Ogura S, Isobe $\mathrm{H}$ Dosaka-Akita H, Ogata A, Shindoh M, Ohbuchi T and Kawakami Y: Intracellular distribution of macrophage migration inhibitory factor predicts the prognosis of patients with adenocarcinoma of the lung. Cancer 89: 334-341, 2000.

28. Tomiyasu M, Yoshino I, Suemitsu R, Okamoto $\mathrm{T}$ and Sugimachi K: Quantification of macrophage migration inhibitory factor mRNA expression in non-small cell lung cancer tissues and its clinical significance. Clin Cancer Res 8: 3755-3760, 2002

29. Wang D, Luo L, Chen W, Chen LZ, Zeng WT, Li W and Huang XH: Significance of the vascular endothelial growth factor and the macrophage migration inhibitory factor in the progression of hepatocellular carcinoma. Oncol Rep 31: 1199-1204, 2014.

30. Chang KP, Lin SJ, Liu SC, Yi JS, Chien KY, Chi LM, Kao HK, Liang Y, Lin YT, Chang YS and Yu JS: Low-molecular-mass secretome profiling identifies HMGA2 and MIF as prognostic biomarkers for oral cavity squamous cell carcinoma. Sci Rep 5: 11689, 2015.

31. Oliveira CS, de Bock CE, Molloy TJ, Sadeqzadeh E, Geng XY, Hersey P, Zhang XD and Thorne RF: Macrophage migration inhibitory factor engages PI3K/AKT signalling and is a prognostic factor in metastatic melanoma. BMC Cancer 14: 630, 2014.

32. Funamizu N, Hu C, Lacy C, Schetter A, Zhang G, He P, Gaedcke J, Ghadimi MB, Ried T and Yfantis HG: Macrophage migration inhibitory factor induces epithelial to mesenchymal transition, enhances tumor aggressiveness and predicts clinical outcome in resected pancreatic ductal adenocarcinoma. Int J Cancer 132: 785-794, 2013

33. Xia HH, Yang Y, Chu KM, Gu Q, Zhang YY, He H, Wong WM, Leung SY, Yuen ST, Yuen MF, et al: Serum macrophage migration-inhibitory factor as a diagnostic and prognostic biomarker for gastric cancer. Cancer 115: 5441-5449, 2009.

34. He LJ, Xie D, Hu PJ, Liao YJ, Deng HX, Kung HF and Zhu SL: Macrophage migration inhibitory factor as a potential prognostic factor in gastric cancer. World J Gastroenterol 21: 9916-9926, 2015.

35. Shi X, Leng L, Wang T, Wang W, Du X, Li J, McDonald C, Chen Z, Murphy JW, Lolis E, et al: CD44 is the signaling component of the macrophage migration inhibitory factor-CD74 receptor complex. Immunity 25: 595-606, 2006.

36. Mitchell RA, Liao H, Chesney J, Fingerle-Rowson G, Baugh J, David J and Bucala R: Macrophage migration inhibitory factor (MIF) sustains macrophage proinflammatory function by inhibiting p53: Regulatory role in the innate immune response. Proc Natl Acad Sci USA 99: 345-350, 2002.

37. Li GQ, Xie J, Lei XY and Zhang L: Macrophage migration inhibitory factor regulates proliferation of gastric cancer cells via the PI3K/AKT pathway. World J Gastroenterol 15: 5541-5548, 2009.

38. Jung $\mathrm{H}$, Seong $\mathrm{HA}$ and $\mathrm{Ha} \mathrm{H}$ : Critical role of cysteine residue 81 of macrophage migration inhibitory factor (MIF) in MIF-induced inhibition of p53 activity. J Biol Chem 283: 20383-20396, 2008

39. Hagemann T, Robinson SC, Thompson RG, Charles K, Kulbe H and Balkwill FR: Ovarian cancer cell-derived migration inhibitory factor enhances tumor growth, progression, and angiogenesis. Mol Cancer Ther 6: 1993-2002, 2007.

40. Li Y, Lu C, Xing G, Zhu Y and He F: Macrophage migration inhibitory factor directly interacts with hepatopoietin and regulates the proliferation of hepatoma cell. Exp Cell Res 300: 379-387, 2004

41. Hu CT, Guo LL, Feng N, Zhang L, Zhou N, Ma LL, Shen L, Tong GH, Yan QW, Zhu SJ, et al: MIF, secreted by human hepatic sinusoidal endothelial cells, promotes chemotaxis and outgrowth of colorectal cancer in liver prometastasis. Oncotarget 6: 22410-24423, 2015.

42. Baron N, Deuster O, Noelker C, Stüer C, Strik H, Schaller C, Dodel R, Meyer B and Bacher M: Role of macrophage migration inhibitory factor in primary glioblastoma multiforme cells. J Neurosci Res 89: 711-717, 2011

43. Kindt N, Laurent G, Nonclercq D, Journé F, Ghanem G, Duvillier H, Gabius HJ, Lechien J and Saussez S: Pharmacological inhibition of macrophage migration inhibitory factor interferes with the proliferation and invasiveness of squamous carcinoma cells. Int J Oncol 43: 185-193, 2013.

44. Ren Y, Chan HM, Fan J, Xie Y, Chen YX, Li W, Jiang GP, Liu Q, Meinhardt A and Tam PK: Inhibition of tumor growth and metastasis in vitro and in vivo by targeting macrophage migration inhibitory factor in human neuroblastoma. Oncogene 25: 3501-3508, 2006. 
45. Pei XJ, Wu TT, Li B, Tian XY, Li Z and Yang QX: Increased expression of macrophage migration inhibitory factor and DJ-1 contribute to cell invasion and metastasis of nasopharyngeal carcinoma. Int J Med Sci 11: 106-115, 2013.

46. Liu H, Chen G, Zhang W, Zhu JY, Lin ZQ, Gong ZC, Wang FQ, Jia J, Sun ZJ and Zhao YF: Overexpression of macrophage migration inhibitory factor in adenoid cystic carcinoma: Correlation with enhanced metastatic potential. J Cancer Res Clin Oncol 139: 287-295, 2013.

47. Hanahan D and Weinberg RA: Hallmarks of cancer: The next generation. Cell 144: 646-674, 2011.

48. Oda S, Oda T, Nishi K, Takabuchi S, Wakamatsu T, Tanaka T, Adachi T, Fukuda K, Semenza GL and Hirota K: Macrophage migration inhibitory factor activates hypoxia-inducible factor in a p53-dependent manner. PLoS One 3: e2215, 2008.

49. Xu X, Wang B, Ye C, Yao C, Lin Y, Huang X, Zhang Y and Wang S: Overexpression of macrophage migration inhibitory factor induces angiogenesis in human breast cancer. Cancer Lett 261: 147-157, 2008

50. Choudhary S, Hegde P, Pruitt JR, Sielecki TM, Choudhary D, Scarpato K, Degraff DJ, Pilbeam CC and Taylor JA III: Macrophage migratory inhibitory factor promotes bladder cancer progression via increasing proliferation and angiogenesis. Carcinogenesis 34: 2891-2899, 2013

51. White ES, Flaherty KR, Carskadon S, Brant A, Iannettoni MD, Yee J, Orringer MB and Arenberg DA: Macrophage migration inhibitory factor and CXC chemokine expression in non-small cell lung cancer: Role in angiogenesis and prognosis. Clin Cancer Res 9: 853-860, 2003

52. Coleman AM, Rendon BE, Zhao M, Qian MW, Bucala R, Xin D and Mitchell RA: Cooperative regulation of non-small cell lung carcinoma angiogenic potential by macrophage migration inhibitory factor and its homolog, D-dopachrome tautomerase. J Immunol 181: 2330-2337, 2008.
53. Hira E, Ono T, Dhar DK, El-Assal ON, Hishikawa Y, Yamanoi A and Nagasue N: Overexpression of macrophage migration inhibitory factor induces angiogenesis and deteriorates prognosis after radical resection for hepatocellular carcinoma. Cancer 103: 588-598, 2005.

54. Girard E, Strathdee C, Trueblood E and Quéva C: Macrophage migration inhibitory factor produced by the tumour stroma but not by tumour cells regulates angiogenesis in the B16-F10 melanoma model. Br J Cancer 107: 1498-1505, 2012.

55. Fu H, Luo F, Yang L, Wu W and Liu X: Hypoxia stimulates the expression of macrophage migration inhibitory factor in human vascular smooth muscle cells via HIF-1alpha dependent pathway. BMC Cell Biol 11: 66, 2010.

56. Ioannou K, Cheng KF, Crichlow GV, Birmpilis AI, Lolis EJ, Tsitsilonis OE and Al-Abed Y: ISO-66, a novel inhibitor of macrophage migration, shows efficacy in melanoma and colon cancer models. Int J Oncol 45: 1457-1468, 2014.

57. Mawhinney L, Armstrong ME, O'Reilly C, Bucala R, Leng L, Fingerle-Rowson G, Fayne D, Keane MP, Tynan A, Maher L, et al: Macrophage migration inhibitory factor (MIF) enzymatic activity and lung cancer. Mol Med 20: 729-735, 2015.

58. Hussain F, Freissmuth M, Völkel D, Thiele M, Douillard P, Antoine G, Thurner P, Ehrlich H, Schwarz HP, Scheiflinger F and Kerschbaumer RJ: Human anti-macrophage migration inhibitory factor antibodies inhibit growth of human prostate cancer cells in vitro and in vivo. Mol Cancer Ther 12: 1223-1234, 2013.

59. Stein R, Mattes MJ, Cardillo TM, Hansen HJ, Chang $\mathrm{CH}$, Burton J, Govindan S and Goldenberg DM: CD74: A new candidate target for the immunotherapy of B-cell neoplasms. Clin Cancer Res 13: 5556s-5563s, 2007.

60. Schulz R and Moll UM: Targeting the heat shock protein 90: A rational way to inhibit macrophage migration inhibitory factor function in cancer. Curr Opin Oncol 26: 108-113, 2014. 